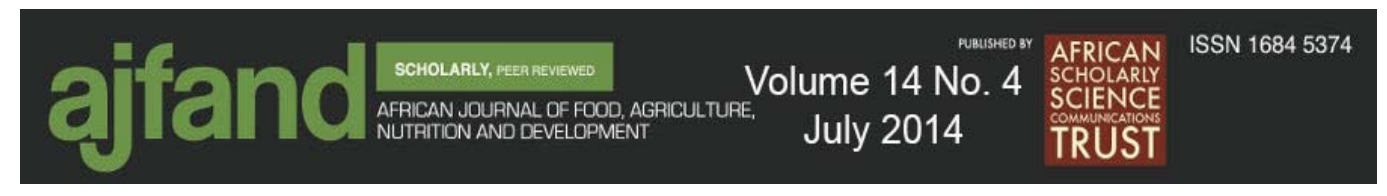

\title{
A NATIONAL SURVEY OF RICE (Oryza sativa L.) GRAIN QUALITY IN SIERRA LEONE I: PERCEPTION OF TRADERS AND CONSUMERS
}

Kamara JS*1, Bockari-Gevao SM', Luseni PJ², Leigh AU¹and RA Cooke ${ }^{3}$

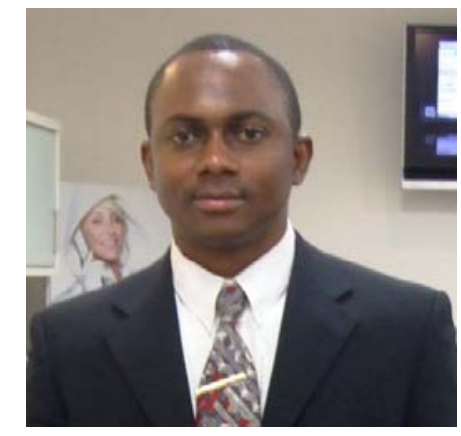

Joseph Sherman Kamara

*Corresponding author’s email: shermankamara@gmail.com / jshermankamara@njala.edu.s1

${ }^{1}$ Department of Agricultural Engineering, Njala University, Njala, Sierra Leone

${ }^{2}$ Department of Industrial Technology, Njala University, Njala, Sierra Leone

${ }^{3}$ Department of Agricultural Engineering, University of Illinois, Urbana, Illinois, USA. 


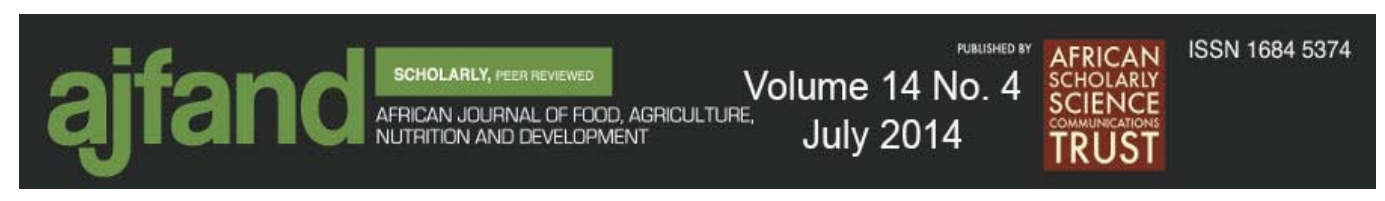

\begin{abstract}
As Sierra Leone approaches self-sufficiency in rice, against a backdrop of agricultural commercialization, the dynamics of the rice grain production and consumption will increasingly be driven by the quality of grains demanded by consumers to be produced by farmers and marketed by traders in the open market. The present study was a national perception survey aimed at establishing the current status of rice grain quality based on the perspectives of traders and consumers interviewed at selected market places in four major cities across the country. In separate interviews conducted with 315 consumers and traders selected at random from 45 markets around the country, individual responses were solicited on the general interests of consumers and traders, as well as the marketing practices and aspirations for the improvement of rice grain quality in the country. Results obtained from the two surveys suggest that the priorities of rice consumers for grain quality were generally similar to those of the traders. For example, between to 63 to 100 per cent ( $84 \%$ all cities) of consumers and 69 to 100 percent ( $88 \%$ all cities) of traders interviewed indicated preference for imported rice, with a significant positive correlation $(\mathrm{r}=0.78)$ between the two groups. Among rice products found in the market, the imported high swelling, long grain rice was shown to be preferred by both traders and consumers, due mostly to the high swelling power and non-seasonal market availability of that grain type. Other results suggest that both traders and consumers desire further improvement in grain quality, even though they do not consider this to be of high priority. The study leads to the conclusion that imported rice products are more popular than local rice products among rice traders and consumers in Sierra Leone. It is speculated that such preference might have been driven directly by the priorities of household food decisions and indirectly by the general socio-economics of food production and consumption in the country.
\end{abstract}

Keywords: Rice grain quality, consumers, Sierra Leone 


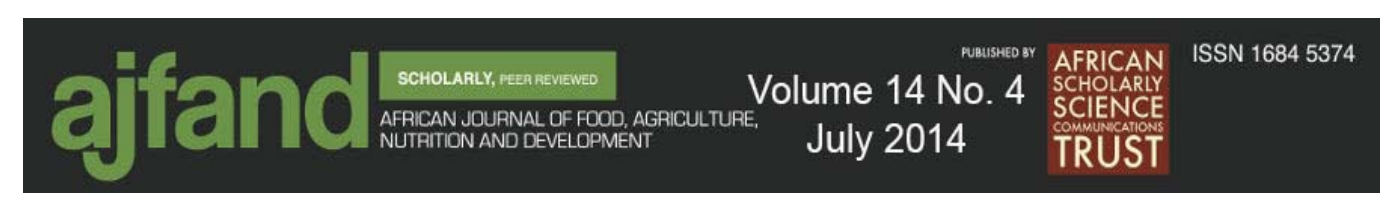

\section{INTRODUCTION}

Rice (Oryza sativa L.) is the most important staple crop in the world, particularly in the developing world. In Sierra Leone, rice is the main staple food crop, and the per capita consumption is among the highest in sub-Saharan Africa [1]. Sustainable growth in the rice sub-sector will increasingly depend on how much is known about the nature and dynamics of the rice production-consumption continuum. Currently, the national rice supply chain consists of both domestic and imported sources [2]. Sierra Leone is a traditional rice growing nation and local supplies come from a large number of smallholder farmers from all parts of the country, amounting to numerous but small seasonal contributions of local rice products. The current scale of production of most of these numerous local suppliers is extremely low and thus total domestic rice production does not meet the local demand for rice [2]. Lack of selfsufficiency in rice production implies that that the deficit is met through imported rice products brought in from elsewhere to augment local supplies. Thus, imported rice supplies constitute a major source of rice consumed in Sierra Leone. Unlike the diffuse nature of local supplies, foreign sources of rice consist of a few, but highly organized importers that bring in large quantities of rice mostly from Asia, especially China, Vietnam, India, Pakistan and Thailand [2].

Despite its value as the main staple food, the rice production system in Sierra Leone remains essentially undeveloped, since it is predominantly in the hands of smallholders who use manual traditional processing and handling practices like head portage for transportation, bare floors for drying, bush sticks for threshing, bamboo fans for winnowing, wooden mortars and pestle for milling and so on. Considering the cause-effect relationship between postharvest facilities and postharvest performance [3], it is logical to expect the domestic rice post production chain to be fraught with many occasions for postharvest losses (both quantitative and qualitative), with the attendant socio-economic implications to which farmers are so accustomed.

Two main types of local rice products exist in Sierra Leone. These are the raw-milled rice which is not subjected to any thermal process other than natural sun-drying and parboiled rice grains, which undergo a major hydrothermal process that results in a number of changes in the physical, biological and chemical properties of the grain [4]. Although parboiling adds to the nutritional, health [5], processing [6] and storage qualities of rice grains, many consumers tend to reject it in favour of raw-milled rice which is said to be more palatable [7,8]. On the other hand, the imported rice market consists of a small proportion of expensive premium rice products, which are only available in special stores or supermarkets visited by only a tiny fraction of the population, and a much larger proportion of various less expensive products (both raw and parboiled) available to all in the open market.

Rice grain quality may be defined on the basis of its properties (example, physical, chemical, storage) or its ability to meet the specific requirements of consumers. From a market perspective, the latter is usually more important. However, global quality factors have been identified for use in different parts of the world to provide a general 


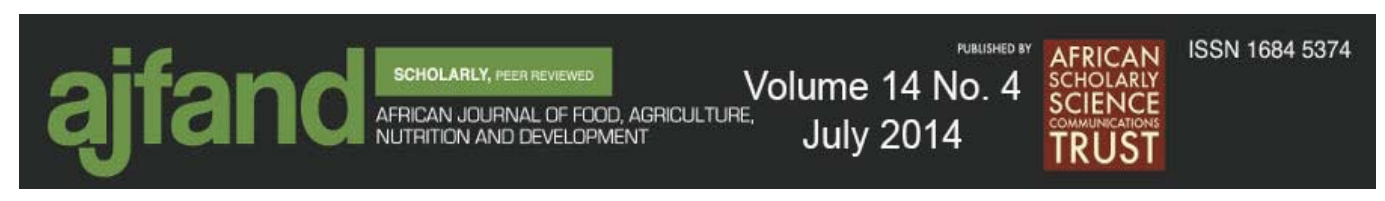

criteria for classifying rice products, and these have been developed to meet these global factors as well as both interests [9], studies show that in practice the definition of rice grain quality is location specific, and the relative importance of the different quality factors is also location specific [10]. As Sierra Leone continues to grapple with the challenges of rice sufficiency and food security, adopting global definitions for rice grain quality, which are usually based on the characteristics of grains, may not be justifiable because consumer discrimination of rice may be based on entirely different areas of interest. For instance, factors like palatability and nutritional quality may be less important to the average household than factors like market availability, price and household satiety (in terms of swelling power). The desires of urban consumers may be found in either one product or the other, (be it local or imported) with location variations $[7,10]$.

In spite of a strong national rice-eating culture going back several centuries [11], it is often speculated that the average Sierra Leonean has very little or no knowledge of rice grain quality. This may be associated with low household income and a general lack of sensitivity to food quality. A shift towards rice gain quality improvement is justified on the basis of the role of rice in the national food security and thrust towards agricultural commercialization. The ability of local rice farmers to compete in local or other high paying markets will depend on the quality of rice they are capable of delivering. Secondly, with increasing local rice supply the domestic demand for high quality rice can only increase as consumers become more discriminatory in the face of abundance [12]. This will become especially evident if prospects for the attainment of self-sufficiency in the next few years [13] are realized. A ground breaking work on the economics of rice grain quality, demonstrated large returns to investment in rice quality improvement, especially in developing countries [14].

Knowledge on the state of rice grain quality is essential for developing effective rice postharvest technologies for grain quality enhancement. So far, this is an apparent gap. This study was conducted to serve as a baseline survey that aims at establishing the nature and status of rice grain quality in Sierra Leone. The survey examines the perspectives of both traders and consumers independently.

\section{RESEARCH METHODOLOGY}

The study was a national market perception survey on the nature of rice grain quality in Sierra Leone with respondents drawn from four major cities across Sierra Leone (Bo, Freetown, Kenema and Makeni). These four cities were selected to represent the best case scenarios of the Southern, Western, Eastern and Northern Regions of the country, respectively. A two-stage sampling approach was used to select markets and, then respondents (Table 1). The same sampling design was used to collect data from 315 traders and consumers independently in 45 local markets across the country (Table 1). Data collection was carried out by separate on-site interviews using separate structured, pre-coded questionnaires. Separate questionnaires were designed for traders and consumers and the questionnaires covered issues such as rice 


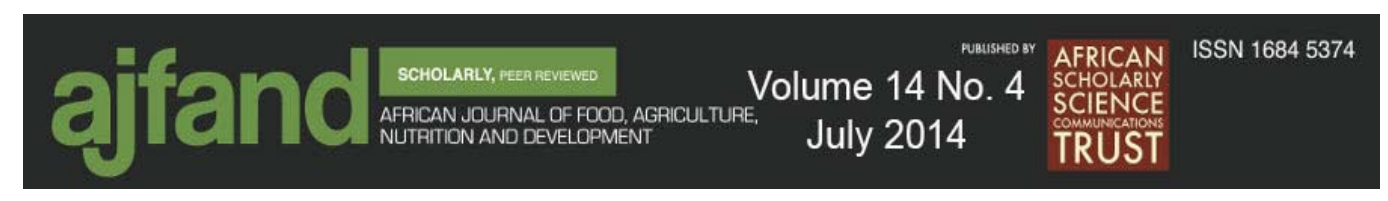

marketing and handling practices, desire for quality and perception on grain quality, consumer and trader preferences. The survey was conducted between June and July 2010, and interviews lasted approximately 20 minutes per respondent. All the responses provided were transferred into a database and analysed with SPSS 16.0 to determine frequencies in cross tabulations.

Consumers interviewed were of various ages and occupational backgrounds, with household sizes ranging from 6 to 11 family members, who consume rice regularly. Traders interviewed had had at least 8 years of experience in rice marketing prior to the survey. The study was designed to reflect the rice quality situation for typical urban consumers in the Western, Northern, Southern, and Eastern Regions of Sierra Leone and present some inherent regional variations in perspectives, preferences and expectations [15].

\section{RESULTS}

\section{Consumers' perception of rice grain quality}

The results obtained on product preference (Figure 1) show a very high preference for imported rice $(84.1 \%)$ among consumers in all four cities, especially Makeni (100\%) and Freetown $(93.3 \%)$.

Preference for local rice products was correspondingly higher among consumers in Bo and Kenema. It was observed that among the smaller proportion of consumers who would rather have a local rice product, raw-milled rice was more preferable (59.6\%) (Figure 1b). Long grain rice was also found to be popular among the majority preferring imported rice. Consumers advanced various reasons for preferring imported rice products (Figure 2). It was evident that the popularity of long grain imported rice was due their relatively higher swelling power.

Asked whether they were satisfied with the quality of rice they bought from the local markets, almost every consumer interviewed indicated that they were satisfied with the quality of both local $(99.1 \%)$ and imported rice products $(95.6 \%)$ available (Table 2). However, despite such widespread endorsements of product excellence by consumers, most of them expressed concerns over certain aspects of grain quality for which they desire some improvement (Figure 3). This suggests that consumers are aware of the existing scope for further grains quality improvement.

In terms of imported rice products, most consumers were concerned over appearance, taste and aroma. There was, however, some evidence of location differences in consumers' desires for the improvement of local rice products. For example, whereas consumers in Freetown and Kenema want the grain appearance to improve, their counterparts in Bo are more interested in improving milling properties. 

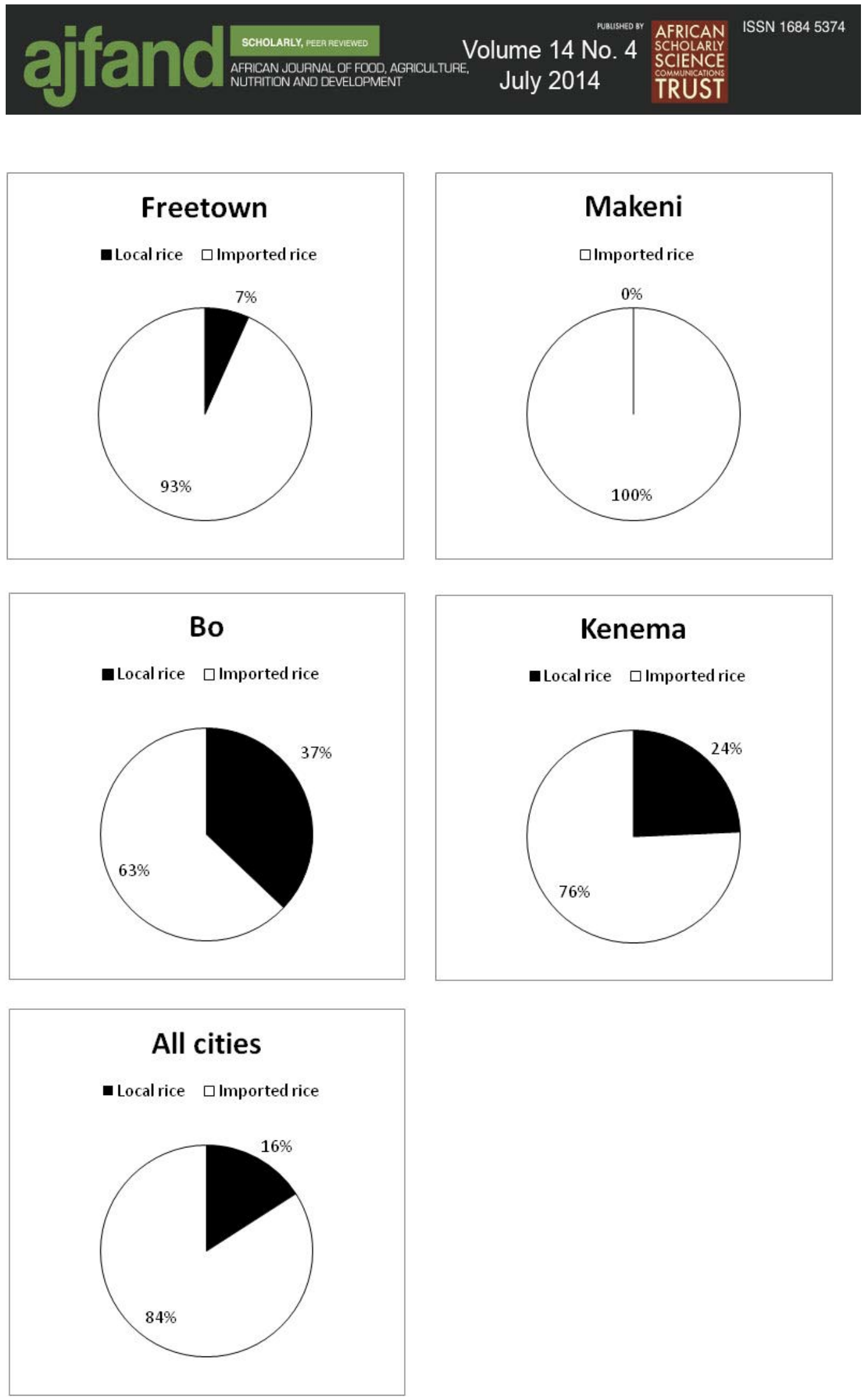

Figure 1(a): Distribution of consumers (\%) by their preference for imported or local rice products 

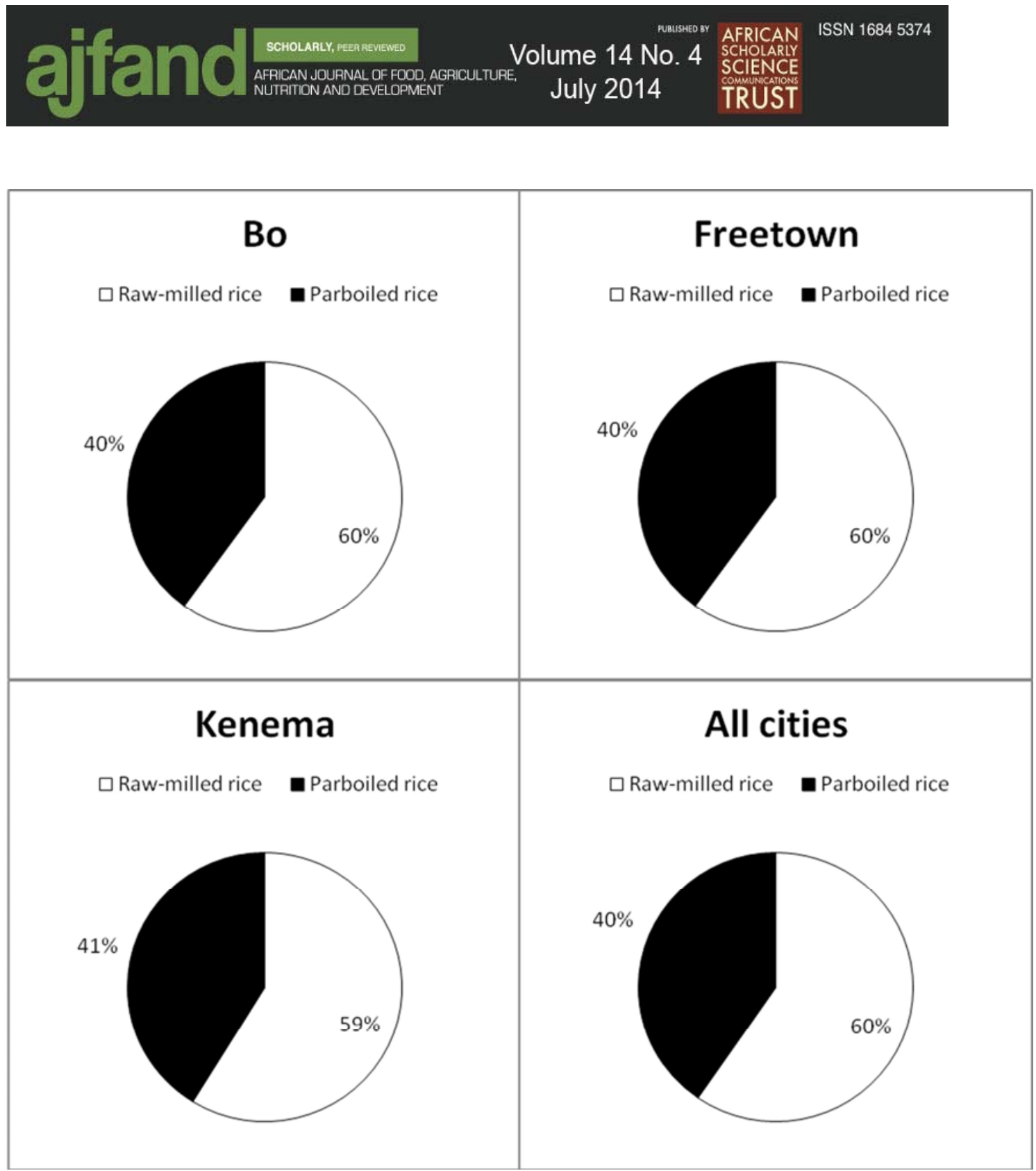

Figure 1(b): Distribution of consumers (\%) by their preference for different local rice products 

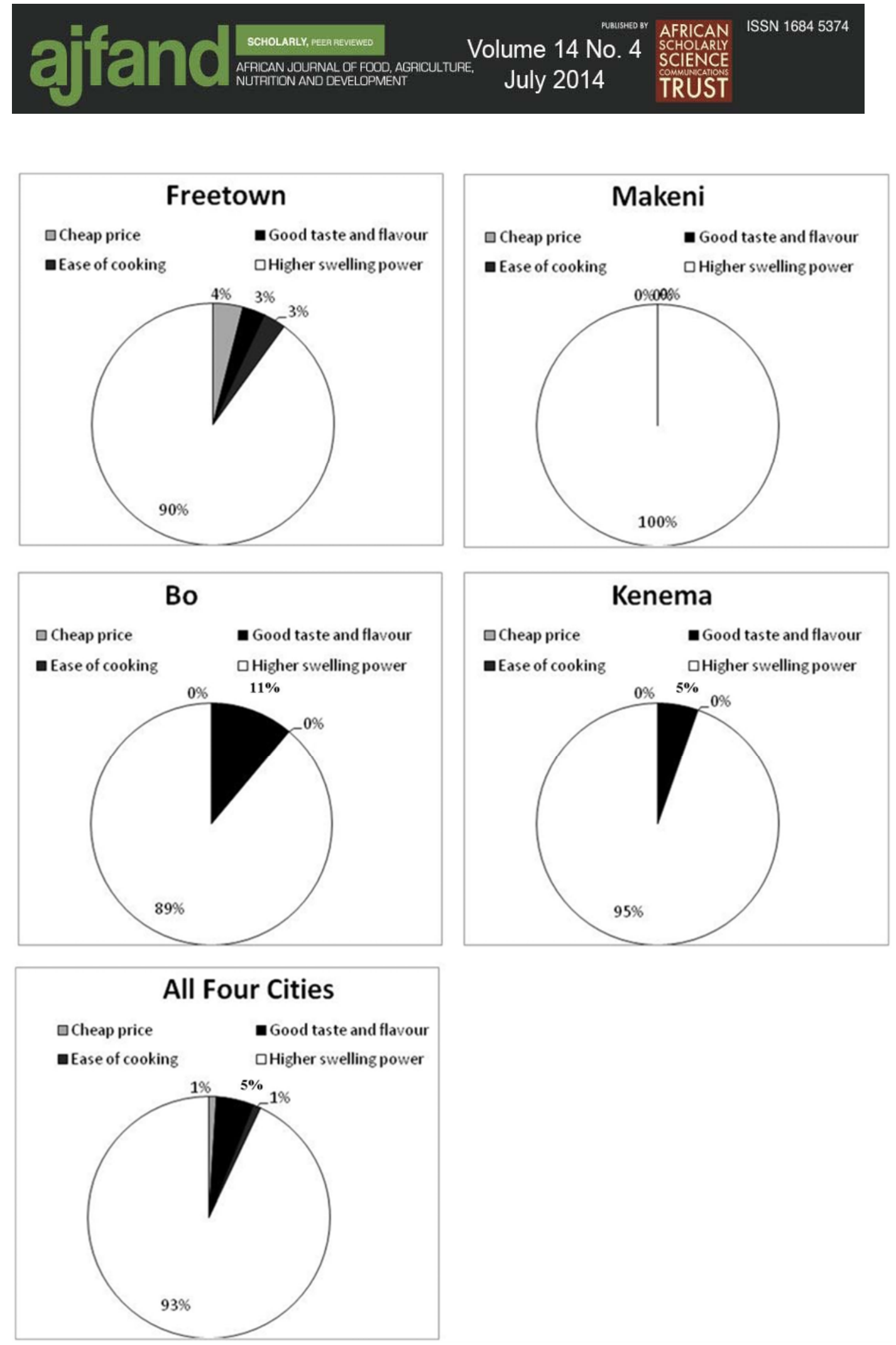

Figure 2: Distribution of consumers interviewed (\%) by the reasons they gave for preferring imported rice products 

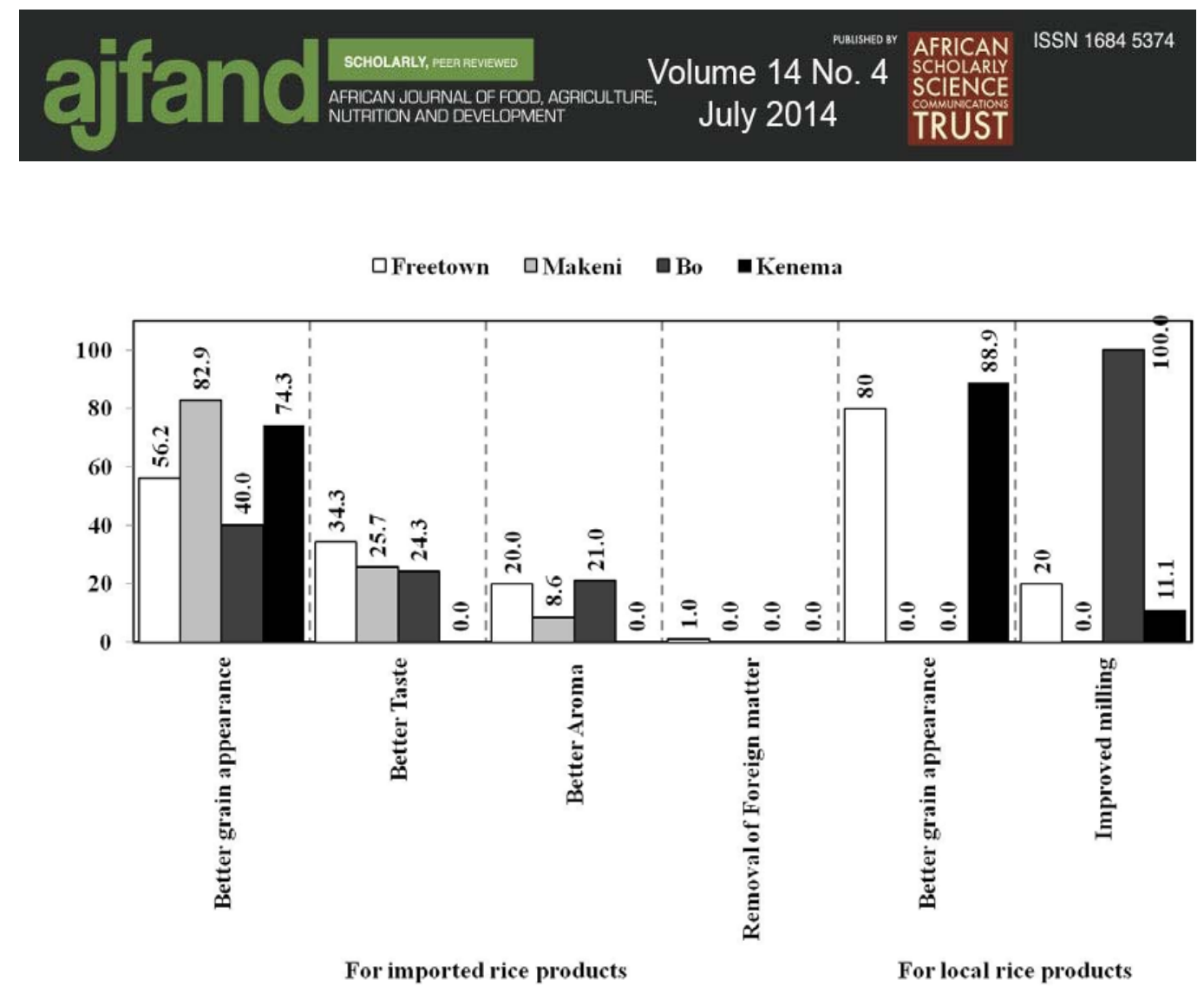

Figure 3: Distribution of consumers (\%) by the kinds of quality improvements they desire in different rice products in their local markets

\section{Rice grain marketing practices}

The marketing practices of rice traders provide useful information on their response to the consumers' demand. Results from trader surveys indicate that almost all traders interviewed $(84.0 \%)$ sell imported rice, with a small proportion selling local rice products (Table 3). This suggests a predominance of imported rice products at the time of the survey (June), which points to seasonal availability of local rice products. Among the few traders found selling local rice products, most $(63.8 \%)$ were found selling raw-milled rice (Figure 4). This result is consistent with data from consumer survey which suggests greater preference for the local raw-milled rice. As with the consumer data there were also apparent locational differences with respect to the proportions of traders selling parboiled or raw milled rice. Whereas a fairly even distribution was recorded for the two products in Bo, there was an apparent a predominance of raw-milled rice in Kenema, and a predominance of parboiled rice in Freetown (Figure 4). 


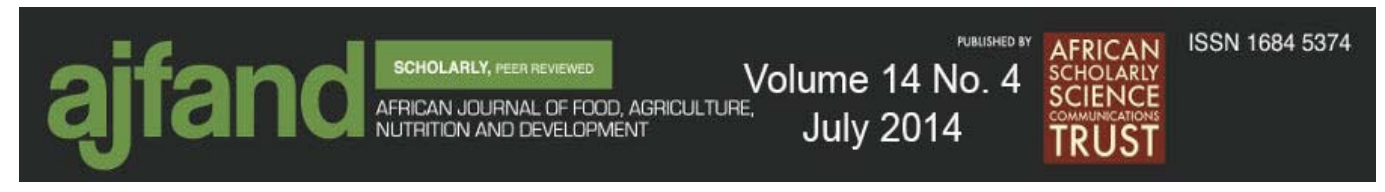

घAll cities $\square$ Kenema $\square$ Bo $\square$ Makeni $\square$ Freetown

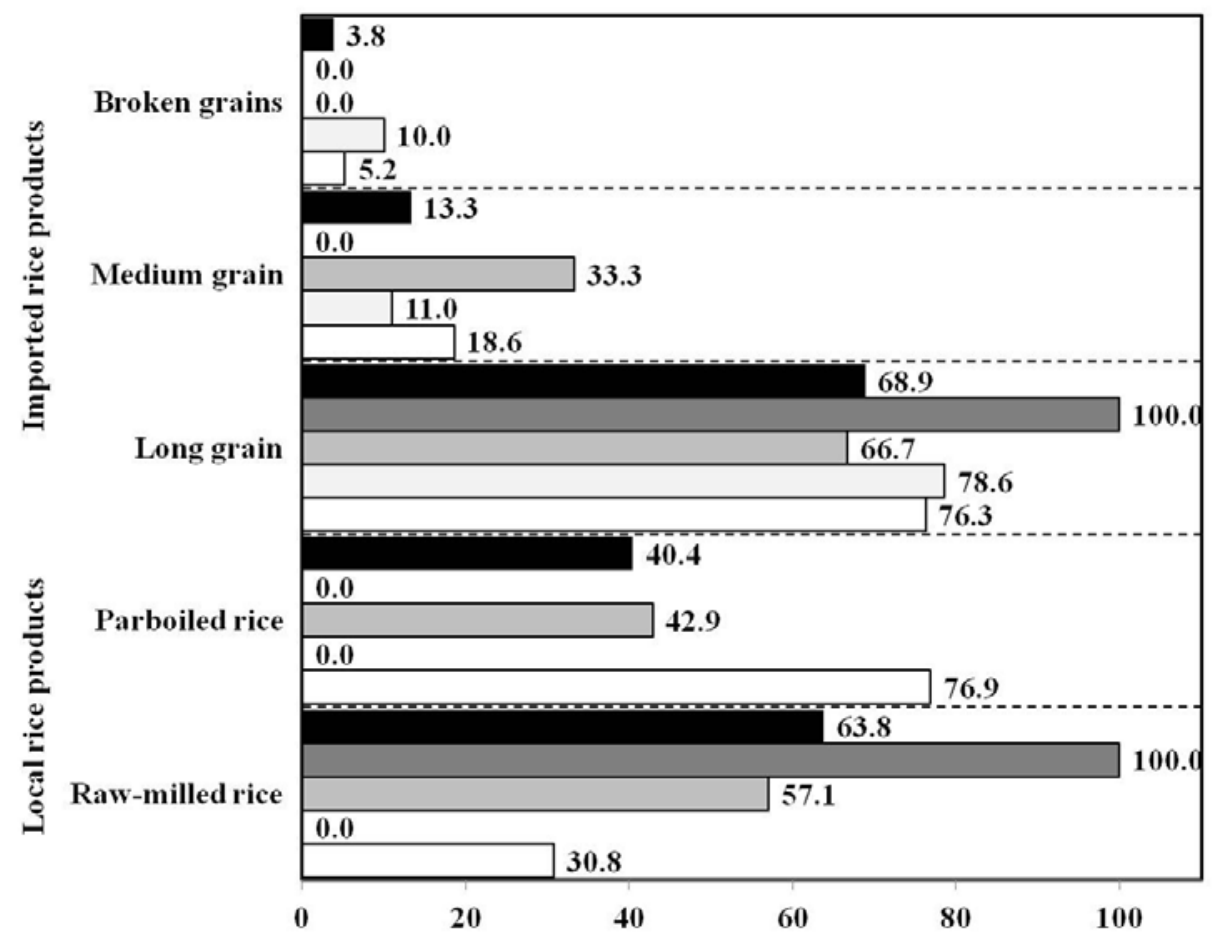

Figure 4: Distribution of rice traders interviewed (\%) by the kinds of local and imported rice products they had for sale at the time of the survey 

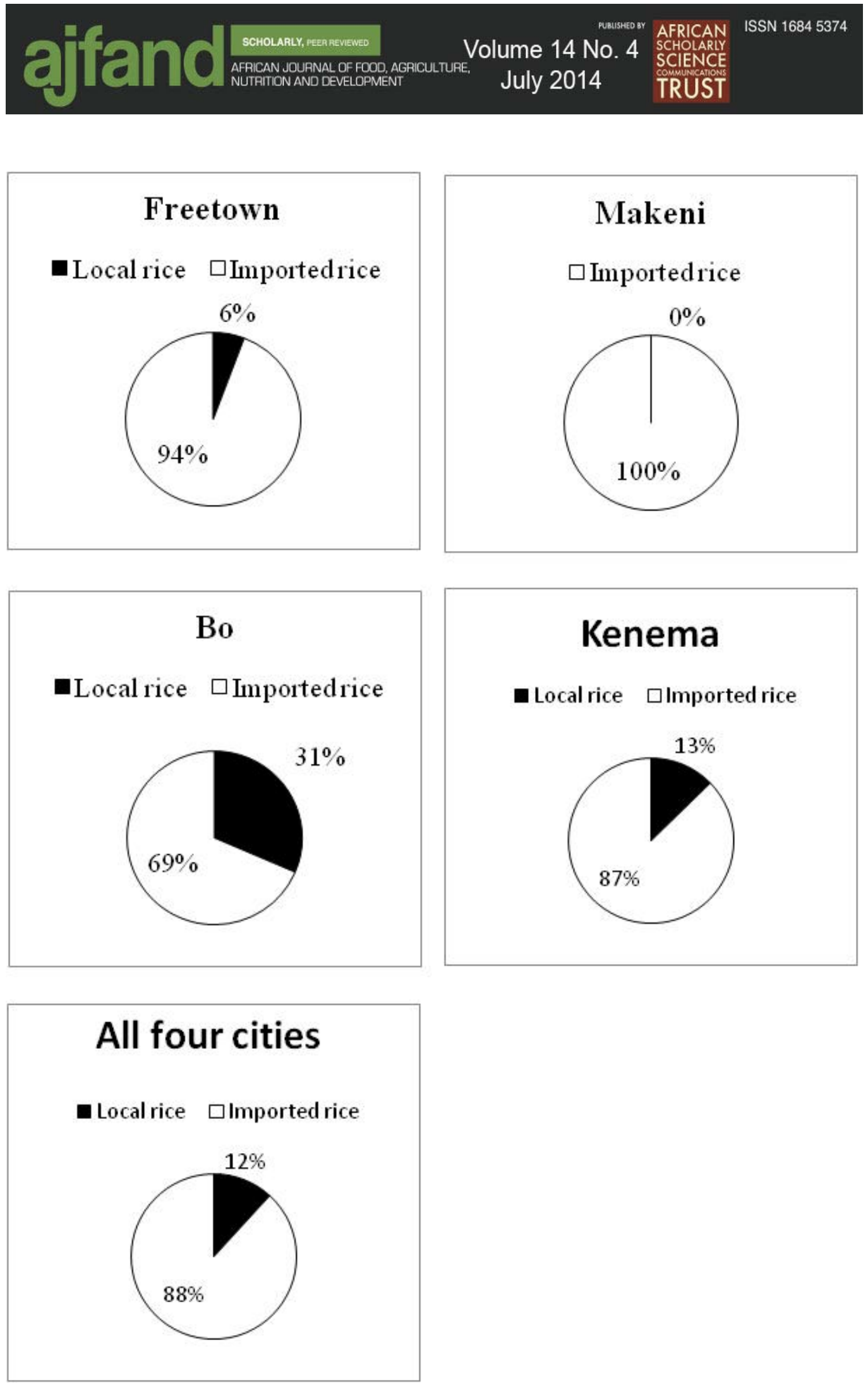

Figure 5: Distribution of rice traders by the type of rice product they consider to be the most profitable 


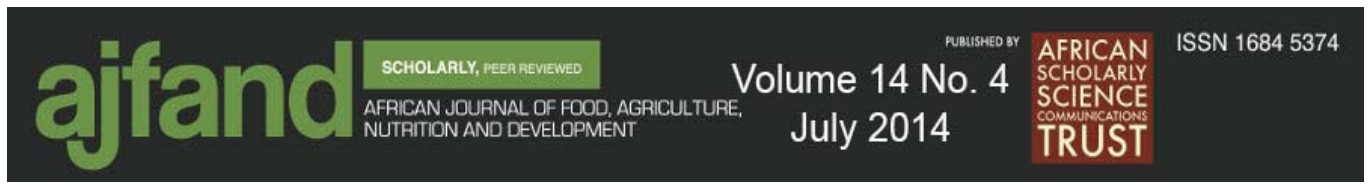

The commercial interest of traders in choosing between local and imported rice was sought in questions soliciting their perceptions on profitability of rice products. Almost all rice traders interviewed $(88 \%)$ believe that it is more profitable to sell imported products than local rice products (Figure 5). Although imported rice was popularly endorsed as more profitable, a remarkable difference in popularity was observed between Makeni (100\%) and Bo (69\%) cities. Rice trading in Sierra Leone normally involves purchase of rice in $50 \mathrm{~kg}$ bags for retailing in small tins (holding between 280 to $320 \mathrm{~g}$ ). Additional data suggests that the perception of greater profits from imported rice is sustained by factors such as the possibility to retail with partial measures, additional income to be acquired through the collection and sale of empty rice sacks (Figure 6) and continuous, non-seasonal availability and a relatively lower wholesale.

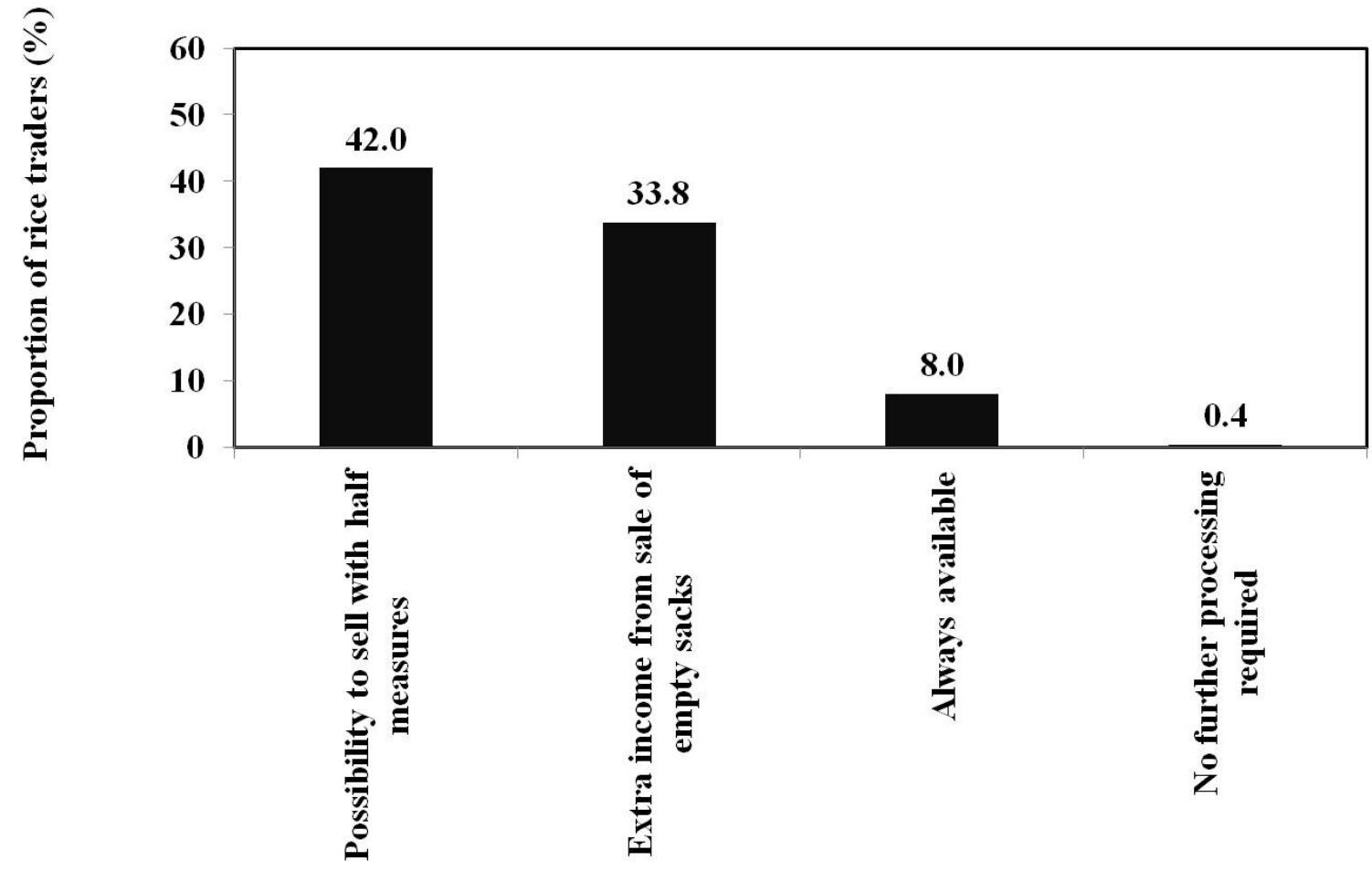

Reasons for considering imported rice to be more profitable

Figure 6: Distribution of rice traders $(\%)$ by the reasons they gave for considering imported rice to be more profitable.

Data from trader survey suggests that rice traders prefer to sell imported rice products for various reasons (Figure 6). Coincidentally, the most common products observed during the trader survey turned out to be the most preferred product in the consumer survey. Indeed a strong positive correlation $(r=0.78)$ was found between the preferences of traders and those of consumers. 


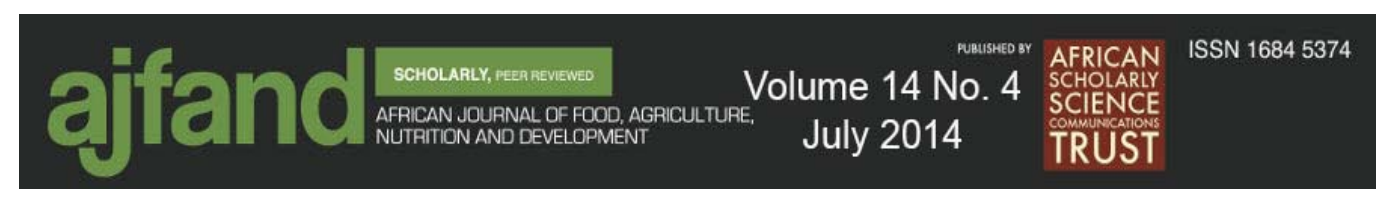

Product preparation is expected to be an important function that traders perform on a regular basis to enhance product presentation for optimum quality. The survey revealed that apart from five traders in Freetown who stated that they normally conduct pre-sale drying in preparation for marketing, the rest (310) do not practice pre-sale preparation (Table 4). Thus, rice retailers sell as bought. Although a rare occurrence, it was interesting to note that that essentially all rice traders get qualityrelated complaints even though they believe their products to be of excellent quality.

\section{DISCUSSION}

The perceptions and expectations of consumers on product quality are important factors that shape the nature of products delivered in the market. Preference for imported rice has also been reported in similar work carried out Ghana, where consumers were said to prefer imported parboiled and raw-milled rice to their local equivalents [7]. The apparent reference for imported rice was consistent among traders and consumers throughout the country. Locational differences in preference detected in this study were minimal, unlike a similar study in which location had a major influence on consumer preference for rice products [10]. Consumers gave various reasons for preferring imported rice but the reasons given by consumers were not related to well known quality factors like milling recovery, aroma and texture of cooked rice [16]. Instead, preference for these products was based on factors related to household satiety in food supply.

In terms of local rice products, the study suggests less popularity for local parboiled rice over raw milled rice. Such outcome was surprising but is probably related to the popular use of inefficient traditional parboiling methods which result in objectionable grain quality [8]. Thus, the nutritional, health and storage benefits of parboiled rice can only reach a relatively small proportion of local rice consumers. The light in the tunnel is that trials involving some improved smallscale rice parboiling systems have resulted in significant improvements in consumer acceptability in parts of West Africa [8]. The popularization of such systems among smallholders can, therefore, serve as an important development in household food and nutrition security.

Swelling property was rated highly as a quality factor of cooked rice and is very important to poor households with large household sizes to allow a higher number of servings per "cup" of rice purchased. Other factors such as price, taste and ease of cooking, though expressed, appeared to be of secondary importance. Concerns expressed over the appearance and taste of rice grains are in line with some of the global organoleptic quality concerns of rice [17].This indicates that rice consumers in Sierra Leone want to see improvements in the quality of rice.

Quality complaints are often associated with consumer disappointments and product failures. When complaints occur, they are meant to provide signals to the producer through the supplier. The rarity of quality complaints among essentially all traders does not necessarily imply a market full of excellent rice products. On the contrary, it suggests that consumers can accommodate inferior products to a certain extent but 


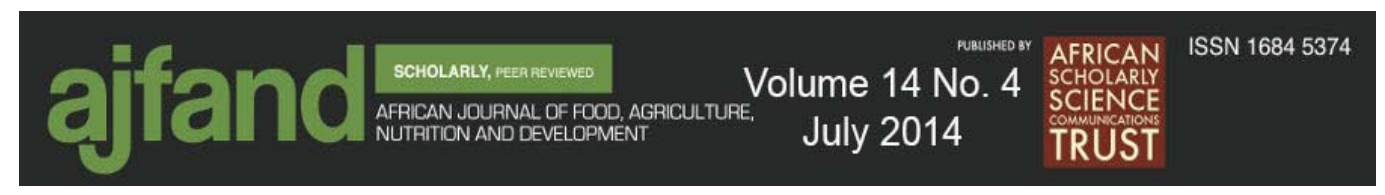

complain from time to time, in extreme cases. Such could be true for consumers who have admitted that they know virtually nothing about the quality factors of rice grains. In the absence of complaints or rejections from consumers, traders are left with little incentive to improve on product presentation.

The study has provided insight into the market preferences for rice grains in Sierra Leone, based on the perspectives of traders and consumers. The results identified imported rice products, especially the Asian long grain rice to be the favourite rice products of urban Sierra Leone. Due to their high swelling power, such rice products match the typical requirements of the predominantly large low income household structure of Sierra Leone. Also, non-seasonality in the supply of imported rice makes it a more secured source of food supply than the local sources whose supply tends to fluctuate over the course of the year.

\section{CONCLUSION}

The study reveals that the general knowledge consumers and traders in Sierra Leone have on rice grain quality is limited to basic household needs and requirements, which are often driven by household income. This factor appears to have been influential in the choice of rice products exchanged in the market. In terms of consumer behaviour, it is understandable that consumers tend to be motivated by the need to match household income with the need for basic household food availability. It is obvious that traders will normally endeavour to cater for the "quality" demanded by consumers. This fact was also reinforced by the results obtained in this study, which show an apparent coincidence in the interests of consumers and traders. This leads to the speculation that the market behaviour of rice traders (in terms of their knowledge of quality, products offered for sale, what they prefer to sell, whether they prepare their products, and so forth) might have been the product of a strong influence interactions between the requirements of consumers and the commercial interests of traders to maximize profits. It is likely that the absence of a popular demand for high quality rice has led to increased popularity for imported rice products and corresponding decline in the demand for local rice, thus culminating in a vicious circle of inattention to the enhancement of local rice grain quality. Sierra Leone is still grappling with the challenges of food security and rice self sufficiency. This means that household preference for available rice products could be significantly influenced by the need to meet the quantitative food requirements of the family. Such a tendency by consumers appears to have dictated the preferences of traders, who tend to like to sell what consumers like to buy. Perhaps for most individuals, the meaning of rice grain quality in Sierra Leone is confined within this market interplay of balancing consumers' household requirements with traders' market supplies. Whereas in most parts of the world the quality of rice grains may be defined based on endogenous physical and chemical properties or cooked rice texture and palatability, this is not the case in Sierra Leone. For ordinary Sierra Leoneans the meaning of rice grain quality seems to be restricted to its ability to satisfy the basic quantitative requirements of households (i.e., in terms of grain swelling power). 


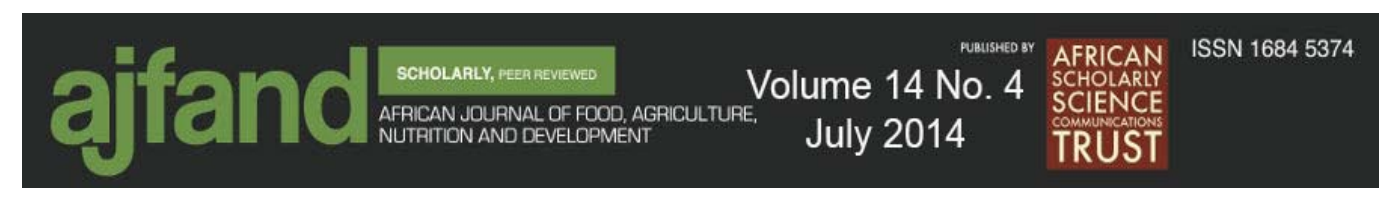

Although the study fails to present an uplifting picture for the quality of rice grain in Sierra Leone, it brought out some key features that characterize the rice market and identifies some of the possible challenges associated with grain quality improvement in the local rice industry. Most of these issues might not have attracted the full attention of researchers and policymakers, who are probably pre-occupied with the business of finding ways to meet the quantitative requirements of national rice selfsufficiency. Perhaps with the imminent attainment of this goal, following the successful implementation of a robust national smallholder commercialization programme, this perspective might change. The smallholder commercialization programme emphasizes capacity enhancement for rice value addition and market efficiency. As the programme rolls out successfully over the next few years the need to meet some of the quality challenges of the rice market will become more and more apparent. Sustainable growth of the local rice industry and the competitiveness of domestic producers, processors and suppliers require that the current quality challenges facing local rice products be given more attention.

The foregoing is a qualitative situation analysis based on farmers' and traders' independent opinions. While they provided useful information on the status of rice grain quality across the country as a whole, the qualitative perceptions of traders do not adequately describe the nature of rice grains available in the country. This can only come from data from an objective analysis of various rice grain samples using standard physical grain quality grading factors. Such data will be presented in the sequel to this article. 


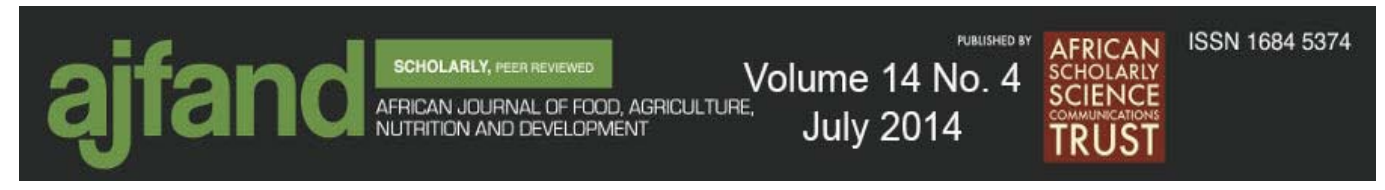

Table1: Details of sampling plan used for data collection during the study

\begin{tabular}{lllccc}
\hline No. & $\begin{array}{c}\text { Region in } \\
\text { the Country }\end{array}$ & Name of City & No. of Markets visited & No. of Rice & No. of Rice \\
& & & & Traders & consumers \\
interviewed & interviewed \\
\hline 1 & Southern & Bo & 10 & 70 & 70 \\
2 & Western & Freetown & 15 & 105 & 105 \\
3 & Eastern & Kenema & 10 & 70 & 70 \\
4 & Northern & Makeni & 10 & 70 & 70 \\
\hline Total & & & 45 & 315 & 315 \\
\hline
\end{tabular}

Table 2: Distribution of consumers (\%) based on their opinions on the quality of rice products available in their local markets

\begin{tabular}{|c|c|c|c|c|}
\hline \multirow[t]{2}{*}{$\begin{array}{c}\text { Name of } \\
\text { City }\end{array}$} & \multicolumn{2}{|c|}{$\begin{array}{l}\text { Consumers' opinion of } \\
\text { local rice products }(n=245)\end{array}$} & \multicolumn{2}{|c|}{$\begin{array}{l}\text { Consumers' opinion of } \\
\text { imported rice products }(n=315)\end{array}$} \\
\hline & $\begin{array}{l}\text { Quality could be } \\
\text { improved }\end{array}$ & $\begin{array}{l}\text { Quality is } \\
\text { excellent }\end{array}$ & $\begin{array}{l}\text { Quality could } \\
\text { be improved }\end{array}$ & $\begin{array}{l}\text { Quality is } \\
\text { excellent }\end{array}$ \\
\hline Freetown & 0.0 & 100.0 & 8.7 & 91.3 \\
\hline Makeni & - & - & 0.0 & 100.0 \\
\hline Bo & 3.2 & 96.8 & 0.0 & 100.0 \\
\hline Kenema & 0.0 & 100.0 & 0.0 & 100.0 \\
\hline All cities & 0.9 & 99.1 & 4.4 & 95.6 \\
\hline
\end{tabular}




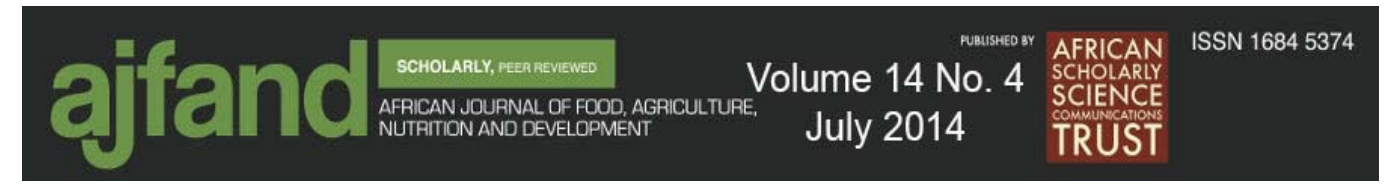

Table 3: Distribution of rice traders interviewed by the types of rice products they sell and their preference for such products

\begin{tabular}{|c|c|c|c|c|}
\hline \multirow{2}{*}{$\begin{array}{c}\text { Name } \\
\text { of } \\
\text { city }\end{array}$} & \multicolumn{2}{|c|}{$\begin{array}{l}\text { Percentage of traders selling local or } \\
\text { imported rice products }\end{array}$} & \multicolumn{2}{|c|}{$\begin{array}{l}\text { Percentage of traders having preference for local } \\
\text { or imported rice products }\end{array}$} \\
\hline & Local rice & Imported rice & Local rice & Imported rice \\
\hline Freetown & 21.0 & 99.0 & 7.6 & 92.4 \\
\hline Makeni & 0.0 & 100.0 & 0.0 & 100.0 \\
\hline Bo & 18.6 & 81.4 & 30.4 & 69.6 \\
\hline Kenema & 20.0 & 80.0 & 20.0 & 80.0 \\
\hline All cities & 15.6 & 84.0 & 13.7 & 86.3 \\
\hline
\end{tabular}

Table 4: Distribution of traders by quality related issues

\begin{tabular}{lccc}
\hline $\begin{array}{c}\text { Name of } \\
\text { City }\end{array}$ & $\begin{array}{c}\text { Percentage of traders } \\
\text { that prepare their } \\
\text { products for the } \\
\text { market }\end{array}$ & $\begin{array}{c}\text { Percentage of traders } \\
\text { receiving quality related } \\
\text { complaints }\end{array}$ & $\begin{array}{c}\text { Percentage of rice traders } \\
\text { that have knowledge in rice }\end{array}$ \\
Freetown & 4.8 & 99.0 & 0.0 \\
Makeni & 0.0 & 100.0 & 0.0 \\
Bo & 0.0 & 100.0 & 0.0 \\
Kenema & 0.0 & 100.0 & 0.0 \\
\hline All cities & 1.3 & 99.7 & 0.0 \\
\hline
\end{tabular}




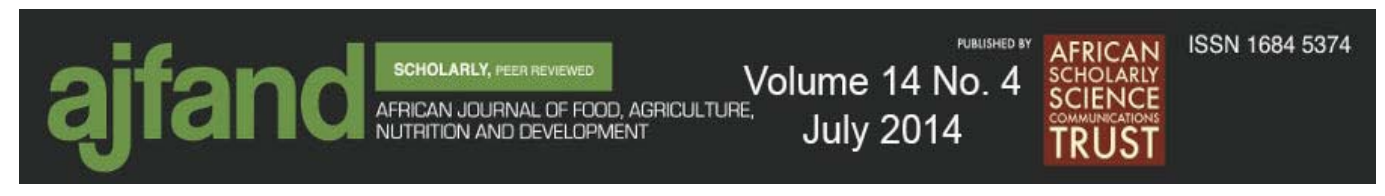

\section{REFERENCES}

1. Africa Rice Centre (WARDA). Africa Rice Trends: Overview of recent developments in the sub-Saharan Africa rice sector. Africa Rice Centre Brief. Cotonou, Benin: Africa Rice Centre (WARDA). 2007: 10p.

2. Spencer DSC, Deen S and C Wilson Economics of rice production in Sierra Leone: Report of a survey in three northern districts. Funded by the Soros Economic Development Fund (SEDF), New York, USA. Available online at http://www.eds-sl.com/docs/ (Accessed in March 2014).

3. Bell MA, Bakker RR, de Paduna DB and J Rickman Rice quality management - principles and some lessons. In: Johnson GI, LV To, N DuyDuc and MC Webb (Eds). Quality assurance in agricultural produce. ACIAR Proceedings 100, 2000: 255-263.

4. Choudhury NH Parboiling and consumer demand for parboiled rice in South Asia. In: Rice Grain Marketing and Quality Issues. Selected papers from the International Rice Research Conference 27-31 August 1990, Seoul, Korea. International Rice Research Institute (IRRI). 1991: 47-54.

5. Widowati S, Santosa BAS, Astawan $M$ and A Khyar Reducing glycaemic index in some rice varieties using parboiling process. Indones. J. Agric. 2010; 2:104-111.

6. Bockari-Gevao SM and A Murray Milling recovery of hand pounding of paddy rice using different pestle ends. International Agricultural Engineering Journal 15. 2006; 1:1-3.

7. Tomlins KI, Manful JT, Larwer $\mathbf{P}$ and L Hammond Urban consumer preferences and sensory evaluation of locally produced imported rice in West Africa. Food Quality and Preference 2005; 79-89.

8. Fofana M, Wanvoeke J, Manful J, Futakuchi K, Van Mele P, Zossou E and TMR Bleoussi Effect of improved parboiling methods on the physical and cooked grain characteristics of rice varieties in Benin. International Food Research Journal18 2011; 715-721.

9. Juliano BO and B Duff Rice grain quality as an emerging priority in rice breeding programs. In: Rice Grain Marketing and Quality Issues. Selected papers from the International Rice Research Conference 27-31 August 1990, Seoul, Korea. International Rice Research Institute (IRRI), Manila. 1991: 5564.

10. Suwannaporn $\mathbf{P}$ and $\mathbf{A}$ LinnemannRice eating quality among consumers in different rice grain preference countries. Journal of Sensory Studies 23. 2008; $1-13$.

11. Carney JA The role of African rice and slaves in the history of rice cultivation in the Americas. Human Ecology 26. 1998; 4: 523-545. 


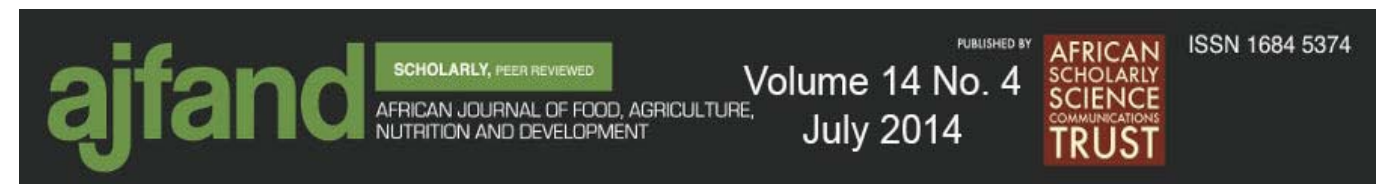

12. Toquero $\mathbf{Z F}$ Consumer demand for rice grain quality. In: Rice Grain Marketing and Quality Issues. Selected papers from the International Rice Research Conference 27-31 August 1990, Seoul, Korea. International Rice Research Institute (IRRI). 1991; 37-46.

13. Food and Agricultural Organization (FAO) of the United Nations Rice Market Monitor 14(2), 2011. Also available on the internet at http://www.fao.org/economic/est/publications/rice-publications/rice-marketmonitor-rmm/en/ (Accessed in September 2013).

14. Unnevehr LJ Consumer demand for rice grain quality and returns to research improvement in South East Asia. American Journal of Agricultural Economics 68. 1986; 3: 634-641.

15. Unnevehr LJ, Juliano BO and CM Perez Consumer demand for rice grain quality in Southeast Asia In: Rice Grain Quality and Marketing. Papers presented at the International Rice Research Conference 1-5 June, 1985, Manila, Philippines. International Rice Research Institute (IRRI). 1985; 1523.

16. Kaosa-ard $M$ and BO Juliano Assessing rice quality characteristics and prices in selected international markets. In: Rice Grain Marketing and Quality Issues. Selected papers from the International Rice Research Conference 2731 August 1990, Seoul, Korea. International Rice Research Institute (IRRI). 1991; 23-35.

17. Srisawas $\mathbf{W}$ and $\mathbf{V} \mathbf{K}$ Jindal Sensory evaluation of cooked rice in relation to water-to-rice ratio and physicochemical properties. Journal of Textural Studies (2006);38:21-41. 